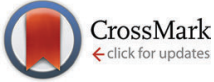

Cite this: Phys. Chem. Chem. Phys., 2015, 17, 26864

Received 20th July 2015,

Accepted 14th September 2015

DOI: $10.1039 / \mathrm{c} 5 \mathrm{cp} 04238 \mathrm{k}$

www.rsc.org/pccp

\section{The effect of surface modification by reduced graphene oxide on the electrocatalytic activity of nickel towards the hydrogen evolution reaction}

\author{
Debabrata Chanda, ${ }^{a}$ Jaromír Hnát, ${ }^{a}$ Ana S. Dobrota, ${ }^{b}$ Igor A. Pašti, ${ }^{b}$ Martin Paidar ${ }^{a}$ \\ and Karel Bouzek*a
}

To find cheap, efficient and durable hydrogen evolution reaction catalysts is one of the major challenges when developing an alkaline water electrolysis system. In this paper we describe an electrochemically reduced graphene oxide (RGO)-modified Ni electrode, which could be used as a pre-eminent candidate for such a system. The experimentally determined characteristics of this electrode showing superior electrocatalytic activity were complemented by density functional theory calculations. Thermodynamic considerations led to the conclusion that $\mathrm{H}$ atoms, formed upon $\mathrm{H}_{2} \mathrm{O}$ discharge on $\mathrm{Ni}$, spill onto the $\mathrm{RGO}$, which serves as an $\mathrm{H}$ adatom acceptor, enabling continuous cleaning of $\mathrm{Ni}$-active sites and an alternative pathway for $\mathrm{H}_{2}$ production. This mode of action is rendered by the unique reactivity of RGO, which arises due to the presence of $O$ surface groups within the graphene structure. The significant electrocatalytic activity and life time ( $>35$ days) of the RGO towards the HER under conditions of alkaline water electrolysis are demonstrated.

\section{Introduction}

The growing energy demands of developed societies occurring in parallel with increasing pressure for environmental protection and pollution reduction have intensified research in the field of environmentally friendly energy production and storage methods. Hydrogen represents one of the most promising energy carriers of the future. ${ }^{1}$ Water electrolysis, as an inseparable part of the hydrogen cycle, represents a technology capable of efficiently converting electrical energy from renewable power sources, such as solar or wind, into the chemical energy of hydrogen., Nowadays, the latest development in electrochemical water splitting research is anion-selective membrane water electrolysis (ASMWE), which has attracted a lot of interest. ${ }^{4-6}$ The advantages of this process are the low hydrogen cross-over, higher flexibility and the possibility to work at elevated pressure. However, many ASMWE devices rely on the use of noble metals like Pt for the hydrogen evolution reaction (HER) despite their scarcity and high cost. ${ }^{5,6}$ One of the key challenges when developing a highly efficient, application-oriented ASMWE system is to find a stable, low cost catalyst for the HER. Mostly, transition metal based electrodes ${ }^{7-9}$ serve as a HER catalyst in alkaline medium, but their activity is

\footnotetext{
${ }^{a}$ Department of Inorganic Technology, University of Chemistry and Technology, Technicka 5, 16628, Prague 6, Czech Republic.E-mail: bouzekk@vscht.cz

${ }^{b}$ Faculty of Physical Chemistry, University of Belgrade, Studentskitrg 12-16, 11158 Belgrade, Serbia
}

far below that of Pt. Carbon-containing compounds like graphene oxide $^{10}$ and graphene ${ }^{11}$ have been characterised as highly active catalysts for the oxygen evolution reaction (OER) in alkaline solution. Moreover, the $\mathrm{Co}_{3} \mathrm{O}_{4} /$ graphene composite material efficiently catalyses the oxygen reduction reaction (ORR) in alkaline medium. ${ }^{12}$ Besides graphene, graphene oxide (GO), i.e. graphene containing a significant amount of oxygen atoms in different functional groups, and reduced graphene oxide (RGO) are also of interest. ${ }^{13-15} \mathrm{MoS}_{2}$ nanoparticles grown on RGO have shown good photocatalytic activity towards the HER in the photoelectrochemical water splitting process. ${ }^{16}$ Yang et al. ${ }^{17}$ reported $\mathrm{WS}_{2}$ deposited on RGO as an efficient HER catalyst for acidic water electrolysis. The porous NiO/RGO hybrid can extensively catalyse the OER in alkaline medium. ${ }^{18}$ However, to the best of our knowledge, no information has been published to date indicating that, in terms of its electrocatalytic activity towards the HER, RGO is comparable to Pt in alkaline water electrolysis. In contrast, the catalytic activities of RGO and GO towards the HER are reported to be fairly poor. ${ }^{19,20}$

Graphene (Geim and Novoselov, 2010 Nobel Prize) has attracted a lot of attention in the recent years due to its potential application in many energy-related technological fields. ${ }^{21-24}$ Graphene is defined as a planar hexagonal ring containing a $\mathrm{sp}^{2}$ hybridised carbon atom with a two-dimensional (2D) honeycomb lattice. ${ }^{25}$ Over the years, graphene-supported metal nanoparticles have attracted a great deal of attention and it was found that graphene acts as an active support in these systems. For example, for hydrogen storage, graphene 
enhances the performance of the composite material through $\mathrm{H}$ spillover, ${ }^{26}$ enabling further tuning of its properties by the introduction of defects and/or dopants. ${ }^{26,27}$ In HER catalysis, the same process is of immense importance, as it enables cleaning of the catalyst surface due to the transfer of discharged $\mathrm{H}$ to the active support where it recombines to $\mathrm{H}_{2}$, allowing the reaction to proceed. ${ }^{28}$

In this paper, a RGO/Ni foam catalyst is described as that, even when compared with a commercial Pt catalyst, exhibits high HER activity in alkaline solution. Additionally, RGO is attached to the Ni foam surface without using a polymeric binder, which is a critical aspect of constructing gas diffusion electrodes by alkaline technology.

The objective of the present study is to prepare RGO from GO on a nickel foam electrode by means of a simple electrochemical method and to verify its suitability for application as a catalyst for the HER in ASMWE. Based on thermodynamic considerations, which relied on density functional theory (DFT) calculations, an atomic-level justification is put forward for the superb catalytic activity of a RGO/Ni foam electrode which is based on $\mathrm{H}$ spillover from the $\mathrm{Ni}$ foam surface to the RGO under HER operating conditions. It is further demonstrated that RGO/Ni foam exhibits good durability for the HER under ASMWE conditions.

\section{Experimental}

\subsection{Preparation of graphene oxide}

In this study the layered graphite oxide (GRO) was produced by the oxidation of graphite using the improved method of Marcano et $a .^{29}$ The prepared GRO is subsequently easily transferred to the GO by the ultrasonic exfoliation method.

$5 \mathrm{~g}$ of $\mathrm{NaNO}_{3}$ (Lachner, Czech Republic, 99.5\%) was dissolved in a $500 \mathrm{ml}$ beaker containing $80 \mathrm{ml}$ of $\mathrm{H}_{2} \mathrm{SO}_{4}$ (Penta, Czech Republic, 95-97\%) and $20 \mathrm{ml}$ of $\mathrm{H}_{3} \mathrm{PO}_{4}$ (Penta, Czech Republic, $85 \%$ ) placed in an ice-water bath. Next, $3 \mathrm{~g}$ of graphite powder (Sigma-Aldrich $\geq 99.9 \%$ ) was introduced into the acid mixture. After 15 minutes of stirring, $6 \mathrm{~g}$ of dry potassium permanganate $\mathrm{KMnO}_{4}$ (Lachner, Czech Republic, 99.5\%) was added to the reaction mixture while keeping its temperature below $20{ }^{\circ} \mathrm{C}$. The solution was stirred for another $2 \mathrm{~h}$ in a water bath at $35{ }^{\circ} \mathrm{C}$ and consequently allowed to stand for 5 days. Subsequently the mixture was diluted by adding $100 \mathrm{ml}$ of water over a period of $20 \mathrm{~min}$. As a consequence, the temperature of the mixture increased to $50{ }^{\circ} \mathrm{C}$. The excess of potassium permanganate was reduced by the addition of $15 \mathrm{ml}$ of $30 \mathrm{wt} \%$ hydrogen peroxide (Lachner, Czech Republic, 30\%). The diluted mixture was washed by the decanting method with $5 \mathrm{wt} \% \mathrm{HCl}$ followed by centrifugation at $1000 \mathrm{rpm}$ for $10 \mathrm{~min}$. This purification process was repeated at least 10 times. Then the mixture was washed by the decanting method with deionized $\mathrm{H}_{2} \mathrm{O}$, followed by centrifugation at $1000 \mathrm{rpm}$ for $10 \mathrm{~min}$. The deionized $\mathrm{H}_{2} \mathrm{O}$ washing process was repeated three times to obtain the graphite oxide (GRO) slurry. It was dried at $50{ }^{\circ} \mathrm{C}$ for 24 hours in a vacuum oven. Graphene oxide (GO) was obtained by ultrasonication of GRO in isopropyl alcohol (Lachner, Czech Republic, 99.99\%) for 4 hours. During the sonication procedure, the temperature was kept below $50{ }^{\circ} \mathrm{C}$.

\subsection{Deposition of reduced graphene oxide (RGO) on the Ni foam electrode}

RGO was deposited on the surface of the electrode electrophoretically. The GO colloid was obtained by dispersing GO powder $(100 \mathrm{mg})$ in isopropyl alcohol $(100 \mathrm{ml})$. Then $10 \mathrm{ml}$ of $1 \mathrm{~mol} \mathrm{dm}^{-3} \mathrm{KOH}$ (Lachner, Czech Republic, 85\%) was added to the solution as a supporting electrolyte. Electrophoretic deposition was performed in a standard two-electrode glass cell at $22{ }^{\circ} \mathrm{C}$. Ni foam $(1.95 \mathrm{~cm} \times 1.95 \mathrm{~cm})$ was used as a cathode. $\mathrm{Pt}$ foil served as an anode. The distance between the two electrodes was $1 \mathrm{~cm}$. RGO deposition was carried out by applying a voltage of $10 \mathrm{~V}$ between the electrodes. During deposition the GO was reduced to RGO. After each deposition of RGO on the Ni foam, it was dried and weighed to control the RGO catalyst loading. The process was continued until an RGO loading of $0.15 \mathrm{mg} \mathrm{cm} \mathrm{cm}^{-2}$ was obtained on the nickel electrode.

\subsection{Material characterization}

Fourier transform infrared spectroscopy (FTIR) analysis was performed using a Thermo Scientific Nicolet iS10 FT-IR spectrometer, USA. Raman measurements were carried out using a dispersive Raman microscope (Senterra R200-L, Bruker Optics, USA) with an excitation wavelength of $514 \mathrm{~nm}$. X-ray photoelectron spectroscopy (XPS) of the samples was performed using an ESCAProbeP (Omicron Nanotechnology Ltd, UK) electron spectrometer. Curve fitting of the core-level XPS lines was carried out using CasaXPS software with a Gaussian-Lorentzian product function and a non-linear Shirley background. The morphology of the deposited RGO was studied by scanning electron microscopy (SEM) (Jeol JSM-6510lv, Japan). The elemental composition of the RGO was determined by energy-dispersive X-ray spectroscopy (EDX) (EDX; NORAN, Jeol, Japan) analysis. TEM was performed on a JEOL JEM-3010 (Japan) field-emission transmission electron microscope with an accelerating voltage of $200 \mathrm{kV}$. For IR, SEM and TEM analysis, the Ni foam was first dissolved in $1 \mathrm{M} \mathrm{HCl}$, then the RGO was collected by a filtration process using a membrane filter (Millipore, JHWP $0.45 \mu \mathrm{m}$, USA).

\subsection{Electrocatalytic study}

The electrochemical tests were carried out using a multichannel potentiostat/galvanostat HEKA PG 310 (HEKA Elektronik, Germany) in a three-electrode configuration with a Pt foil counter-electrode and a $\mathrm{Hg} / \mathrm{HgO}$ reference electrode in a $1 \mathrm{~mol} \mathrm{dm}{ }^{-3} \mathrm{KOH}$ aqueous electrolyte (0.098 V vs. SHE at room temperature). During this measurement, nickel foam or RGO-modified Ni foam was used as a working electrode. A Vulcan XC-72R supported Pt catalyst (30\% Pt-C) (E-Tek Inc., USA) was used on the cathode side as a standard material for comparison with $\mathrm{RGO} / \mathrm{Ni}$ foam. The Pt catalyst was attached to the $\mathrm{Ni}$ foam electrode by an anionselective quaternized polyphenylene oxide (qPPO) binder. For more detailed information on the preparation of the cathode catalyst layer, refer to ref. 5. The linear sweep voltammetry (LSV) 
curves were collected in the potential range of $-0.6 \mathrm{~V}$ to $-1.45 \mathrm{~V}$ at a potential scan rate of $10 \mathrm{mV} \mathrm{s}^{-1}$. The cyclic voltammograms (CV) were recorded in the potential range of $0 \mathrm{~V}$ to $-0.8 \mathrm{~V}$ at a scan rate of $10 \mathrm{mV} \mathrm{s}^{-1}$. All electrochemical experiments were carried out at a temperature of $22{ }^{\circ} \mathrm{C}$ and at an ambient pressure.

\subsection{Preparation of the MEA for alkaline water electrolysis}

The heterogeneous anion-selective membrane (27.3 wt\% low density polyethylene, $6.7 \mathrm{wt} \%$ poly(ethylene glycol-ran-propylene glycol), 66 wt\% anion-selective resin particles, Dowex Marathon A) was used for the water electrolysis experiments. After being cut to the appropriate dimensions, the membrane was activated according to the procedure described in ref. 30 . The ion-exchange capacity and ionic conductivity of the activated membrane were found to be $2 \mathrm{mmol} \mathrm{g}^{-1}$ and $5.6 \mathrm{~S} \mathrm{~m}^{-1}$ at $50{ }^{\circ} \mathrm{C}$ respectively. ${ }^{30} \mathrm{RGO}$ containing $\mathrm{Ni}$ foam was used as a cathode and bare nickel foam as an anode in an alkaline electrolyser. Gold-plated nickel was used as a current feeder. The cell was completed by two steel terminal plates separated from the current feeder by a PEEK plate. An electrolysis cell, constructed using both a bare nickel foam cathode as well as an anode, was used as a standard set-up for purposes of comparison. In addition, Ni foam with carbonsupported Pt was adopted as a cathode catalyst for comparison with RGO/Ni foam.

A single-cell alkaline water electrolyser was operated at $50{ }^{\circ} \mathrm{C}$ using $10 \mathrm{wt} \% \mathrm{KOH}$ solution as a liquid electrolyte. The performance of the prepared catalyst was evaluated by determining the load curves in a cell voltage range of 1.5 to $2.0 \mathrm{~V}$ using stabilised power source Statron 3251.1 (Statron Gerätetechnik GmbH, Germany). For more detailed information on the experimental arrangement, refer to ref. 30 .

\subsection{DFT calculations}

Periodic DFT calculations were performed using the PWscf code of the Quantum ESPRESSO distribution. ${ }^{31}$ Ultrasoft pseudopotentials were generated on the GGA-PBE level of approximation. ${ }^{32}$ The kinetic energy cutoff was $30 \mathrm{Ry}$, while the charge density cutoff was 448 Ry. Pristine graphene (p-graphene) was modeled using a layer consisting of 32 carbon atoms within an orthorhombic supercell with dimensions amounting to $9.88 \times 8.65 \times 14 \AA$. The first irreducible Brillouin zone was sampled by $\Gamma$-centered $4 \times 4 \times 1$ set of $k$-points generated by the general MonkhorstPack scheme. ${ }^{33}$ Convergence with respect to the vacuum layer thickness and $k$-point mesh was confirmed. Oxygen defects were introduced on both sides of the graphene layer to model RGO. Epoxy- and hydroxyl-graphene were modeled with $\mathrm{O}: \mathrm{C}$ ratios amounting to $1: 8$ in both cases and are denoted hereafter as $\mathrm{C}_{32} \mathrm{O}_{4}$ and $\mathrm{C}_{32}(\mathrm{OH})_{4}$. RGO models were obtained upon cell relaxation in an $X Y$ plane and relaxation of all atoms contained within the supercell. Relaxation was allowed until the forces acting on the atoms were below $0.025 \mathrm{eV} \AA^{-1}$ and the change in the total energy of the system was below $1 \mathrm{meV}$ (both criteria had to be satisfied). The nickel surface was modeled with (001) orientation using a $(2 \times 2)$ cell with 4 metal layers and a $14 \AA$ thick vacuum layer. Integration of the first irreducible Brillouin zone was done using a $4 \times 4 \times 1$ set of $k$-points. Relaxation of the adsorbate layer and the top two surface layers was allowed in all directions. When subsurface hydrogen sorption in Ni was studied, only a bottom Ni layer was kept fixed.

The strength of hydrogen interaction with the RGO and $\mathrm{Ni}(001)$ surfaces was measured by hydrogen binding energy $\left(E_{\mathrm{b}}\right)$ defined as:

$$
E_{\mathrm{b}}=E_{\text {subs }+\mathrm{H}}-\left(E_{\text {subs }}+E_{\mathrm{H}}\right)
$$

where $E_{\text {subs+H}}, E_{\text {subs }}$ and $E_{\mathrm{H}}$ stand for the total energy of the substrates with bonded hydrogen, the total energy of the substrate and the total energy of the isolated $\mathrm{H}$ atom. Alternatively, the strength of the hydrogen-RGO interaction can be referred to molecular $\mathrm{H}_{2}$ as $\mathrm{H}$ adsorption energy $\left(E_{\text {ads }}\right)$ :

$$
E_{\text {ads }}=E_{\text {subs }+\mathrm{H}}-\left(E_{\text {subs }}+\frac{1}{2} E_{\mathrm{H}_{2}}\right)
$$

where $E_{\mathrm{H}_{2}}$ stands for the total energy of the isolated $\mathrm{H}_{2}$ molecule. $E_{\mathrm{b}}$ and $E_{\text {ads }}$ are mutually connected by a half of the $\mathrm{H}_{2}$ bond energy $\left(E_{\mathrm{b}}=E_{\text {ads }}-2.26 \mathrm{eV}\right)$. For the investigation of the interaction of $\mathrm{H}$ with the RGO model surfaces, all atoms contained within the supercell were fully relaxed. For the calculations with Ni surfaces, spin-polarization was taken into account. Spin-polarization effects in calculations with RGO surfaces were investigated explicitly.

\section{Results and discussion}

\subsection{Physical characterization}

The FTIR spectra of the prepared GO and RGO were recorded (Fig. 1A). The spectrum of GO contains a broad and intense absorption band at $3422 \mathrm{~cm}^{-1}$, corresponding to the $\mathrm{O}-\mathrm{H}$ stretching vibrations and bands at 1704 and $1010 \mathrm{~cm}^{-1}$, which are assigned to the $\mathrm{C}=\mathrm{O}$ and $\mathrm{C}-\mathrm{OH}$ stretching vibrations of $\mathrm{COOH}$ groups, respectively. After the reduction of GO, the intensity of the bands of the $\mathrm{O}-\mathrm{H}, \mathrm{C}-\mathrm{O}$ and $\mathrm{C}=\mathrm{O}$ groups decreased dramatically, indicating the occurrence of a deoxygenation reaction. Fig. 1B shows the Raman spectra of GO and RGO-coated Ni foam. Ni foam
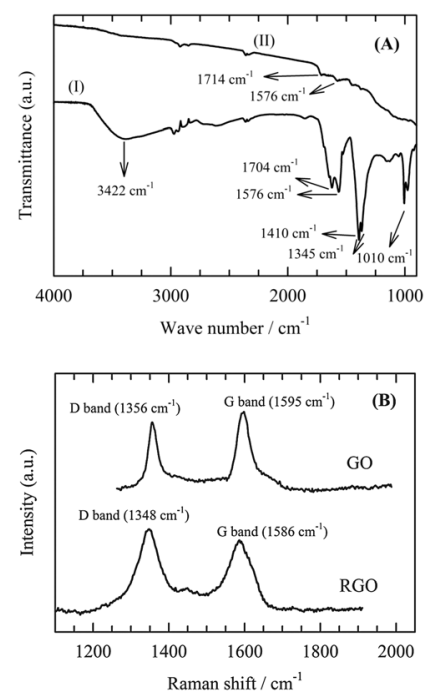

Fig. 1 (A) FT-IR spectra of (I) GO and (II) RGO. (B) Raman spectra of GO and RGO. 
does not appear in Raman spectra. ${ }^{10}$ GO shows two Raman bands, the $\mathrm{D}$ band and $\mathrm{G}$ band at 1356 and $1595 \mathrm{~cm}^{-1}$, respectively. Whereas the $\mathrm{D}$ band $\left(\mathrm{sp}^{3}\right)$ corresponds to the disorder line, the $\mathrm{G}$ band $\left(\mathrm{sp}^{2}\right)$ indicates the order line.

After GO had been reduced to RGO, the D band became more prominent and shifted from $1356 \mathrm{~cm}^{-1}$ to $1348 \mathrm{~cm}^{-1}$ due to the reduction in size of the in-plane $\mathrm{sp}^{2}$ domains. At the same time, the $\mathrm{G}$ band shifted from $1595 \mathrm{~cm}^{-1}$ to $1586 \mathrm{~cm}^{-1}$. This corresponds to the dominating first-order scattering of the $\mathrm{E}_{2 \mathrm{~g}}$ mode representing the $\mathrm{sp}^{2}$ domain of graphite. The lattice defects arise due to the presence of carboxyl, hydroxyl and epoxide groups on the carbon basal plane.

The decrease of the peak intensity ratio $I(D): I(G)$ between the $\mathrm{D}$ band and the $\mathrm{G}$ band represents a decrease in the number of defects in the carbon basal plane. In the present case, ration values of 0.96 and 1.15 were obtained for GO and RGO, respectively. This result indicates a significant number of defects in the RGO basal plane, which is higher for RGO than for GO.

The C:O ratios determined by X-ray photoelectron spectroscopy (XPS) (survey scan, Fig. 2A and B) had values of 2.16 and 3.1 for GO and RGO, respectively. This provides additional evidence that GO electrochemical reduction was incomplete. Some oxygen-containing groups remain maintained in the structure even after its application. The C1s XPS spectrum (Fig. 2C) of the GO sheets showed a sharp peak at $284.57 \mathrm{eV}$, which corresponded to aromatic C-C (40\%) bonds of carbon atoms in a conjugated honeycomb lattice. Peaks at 285.74, 288.51 and $290 \mathrm{eV}$ could be attributed to the $\mathrm{C}$ in $\mathrm{C}-\mathrm{O}$ or $\mathrm{C}-\mathrm{OH}(21 \%)$, carbonyl $(\mathrm{C}=\mathrm{O}, 15 \%)$ and carboxylate $(\mathrm{O}-\mathrm{C}=\mathrm{O}$, $24 \%$ ) groups, respectively. Oxygen-containing groups are present due to the harsh oxidation of the $\mathrm{sp}^{2}$ atomic structure of graphite. The C1s spectra of RGO in Fig. 2D indicate that the oxygen-containing carboxylate groups were completely reduced after the electrochemical reduction. Thus, the $\mathrm{C}=\mathrm{O}(4 \%)$ bond signal was also significantly reduced. Based on Fig. 2D, it can be stated that the peak ratio of the $\mathrm{C}-\mathrm{C}(49 \%)$ bond increases. This is due to the formation of the $\mathrm{C}-\mathrm{C}$ skeleton by the reduction
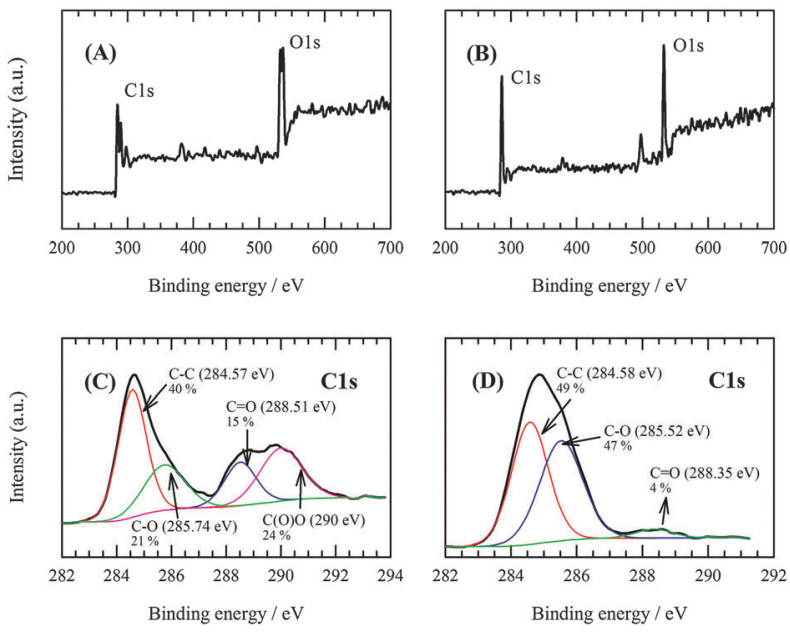

Fig. 2 XPS survey spectra of (A) GO and (B) RGO. XPS C1s and fitting curve of (C) GO and (D) RGO. process of the oxygen-containing species. On the other hand, the intensity of the peak corresponding to the $\mathrm{C}-\mathrm{O}$ or $\mathrm{C}-\mathrm{OH}(47 \%)$ bond increased, which could be explained by the reduction of $\mathrm{C}=\mathrm{O}$ and $\mathrm{O}-\mathrm{C}=\mathrm{O}$ upon formation of these groups. It can be concluded that the observations described prove that the reduction of GO to RGO does proceed, but only to a certain degree. A significant portion of more stable oxygenated functional groups remains preserved even after the reduction.

Fig. 3A shows RGO-coated Ni foam. This, together with a closer view shown in Fig. 3B, documents the fact that the RGO forms a continuous film over the $\mathrm{Ni}$ foam framework. EDX elemental mapping (Fig. 4) supported the presence of Ni (support), $\mathrm{C}$ (RGO) and $\mathrm{O}$ (residual oxygen functional groups) elements in the RGO-Ni foam. Fig. 5 shows a SEM image of the unsupported RGO (without Ni foam), revealing its ruffled structure after exfoliation. The morphology of RGO resembles a thin curtain, which indicates the overlap between the individual RGO films. Fig. 6 shows the TEM images of the resulting RGO (without Ni foam) material. It exhibits a typical wrinkled structure caused by irregularities and folding of the sheets. The resulting images reveal that RGO forms a crumpled, multilayer thin film on the Ni surface.

\subsection{Electrochemical characterization}

The electrocatalytic activity of the RGO-modified nickel foam electrode towards the HER was investigated in $1 \mathrm{~mol} \mathrm{dm}^{-3} \mathrm{KOH}$ solution by means of LSV and CV and compared with bare $\mathrm{Ni}$
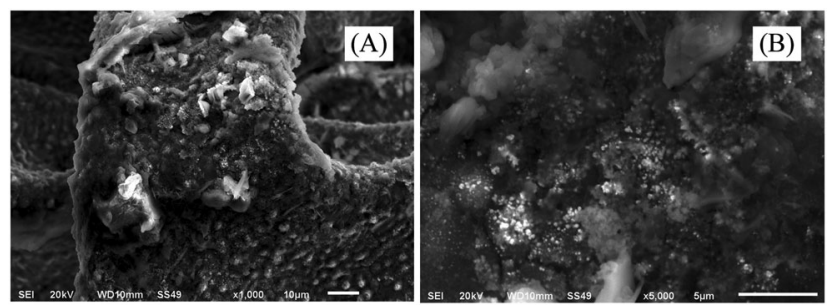

Fig. 3 SEM images of the RGO-coated Ni foam electrode.
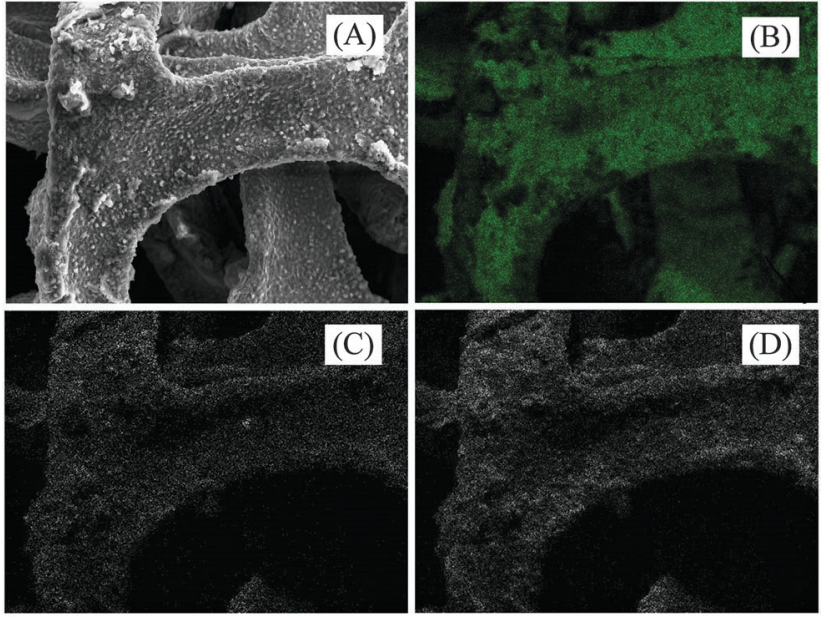

Fig. 4 (A) SEM image of RGO-coated Ni foam, (B-D) EDX elemental distributions of $\mathrm{Ni}, \mathrm{C}$ and $\mathrm{O}$, respectively for the $\mathrm{RGO}-$ nickel foam electrode. 

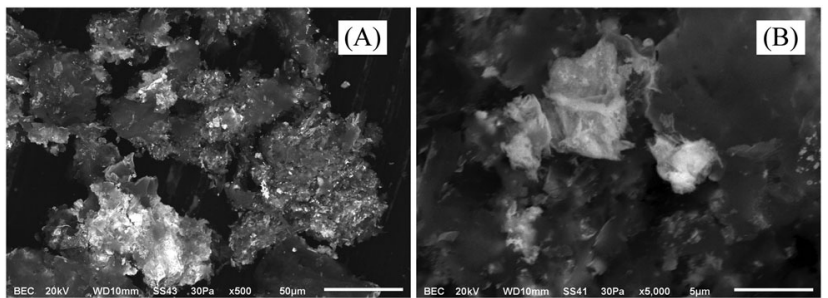

Fig. 5 SEM images of the multilayer structure of RGO (without Ni foam) at different magnifications.
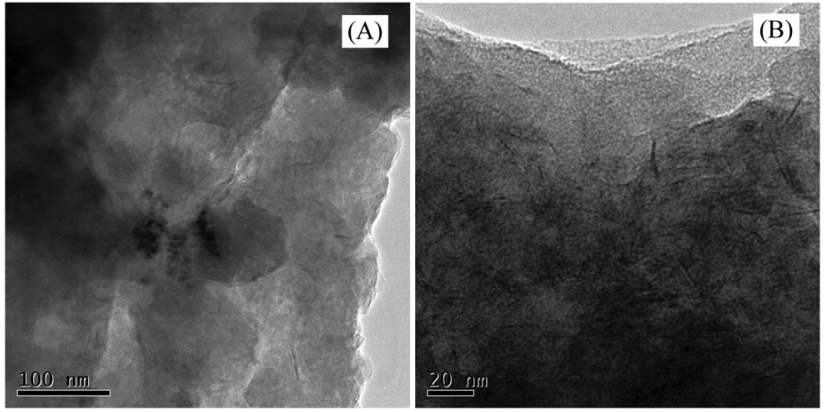

Fig. 6 TEM images of the multilayer structure of RGO (without Ni foam).

foam and a Pt-C/Ni foam electrode. In Fig. 7A, the LSV curve from $\mathrm{RGO} / \mathrm{Ni}$ foam exhibits HER electrocatalytic activity higher than that of $\mathrm{Pt}-\mathrm{C} / \mathrm{Ni}$ foam and $\mathrm{Ni}$ foam electrodes. The $\mathrm{CV}$ curves of $\mathrm{Ni}$ foam and $\mathrm{RGO} / \mathrm{Ni}$ foam electrodes (Fig. 7B) are similar in shape and show the same features. This also led us to conclude that the RGO layer formed on $\mathrm{Ni}$ foam is permeable to the electrolyte, while only a fraction of $\mathrm{Ni}$ surface is blocked by $\mathrm{RGO}$, as deduced from the reduction of the current response of $\mathrm{RGO} / \mathrm{Ni}$ foam in comparison to the bare $\mathrm{Ni}$ foam. Constructed Tafel plots (Fig. 7C) for bare Ni foam, RGO/Ni foam and Pt-C/Ni foam yielded Tafel slopes and are summarised in Table 1.

A Tafel equation in the form of

$$
\eta=b \log j+a
$$

was used, where $j$ is the current density and $\eta$ stands for the electrode overpotential, $a$ and $b$ are the Tafel intercept and the Tafel slope, the latter being an intensive quantity. Thus, it only depends on the reaction mechanism and not on the size of the electrode. For this reason $b$ is an important parameter. It is often used in determining the reaction mechanism or its ratedetermining step because the Tafel slope has defined values for a number of known electrode reactions and reaction mechanisms. In an alkaline environment, the HER starts with the proton discharge at the cathode (Volmer reaction, eqn (4)):

$$
\mathrm{M}+\mathrm{H}_{2} \mathrm{O}+\mathrm{e}^{-} \Leftrightarrow \mathrm{MH}_{\mathrm{ads}}+\mathrm{OH}^{-} \text {Volmer }
$$

This step is followed either by an electrodesorption step (Heyrovsky reaction, eqn (5)),

$$
\mathrm{MH}_{\mathrm{ads}}+\mathrm{H}_{2} \mathrm{O}+\mathrm{e}^{-} \Leftrightarrow \mathrm{M}+\mathrm{H}_{2}+\mathrm{OH}^{-} \text {Heyrovsky }
$$

or by a hydrogen recombination step (Tafel reaction, eqn (6)),

$$
\mathrm{MH}_{\mathrm{ads}}+\mathrm{MH}_{\mathrm{ads}} \Leftrightarrow \mathrm{H}_{2}+2 \mathrm{M} \quad \text { Tafel }
$$

The distinction between steps (4), (5) and (6) as the ratedetermining steps is usually accomplished in terms of evaluating the Tafel slope of the reaction or by calculating the rate constants of the forward and backward reactions. According to the general model of the HER mechanism, if the Volmer reaction, eqn (4), is the rate-determining step, the resulting Tafel plot should yield a slope of $120 \mathrm{mV} \mathrm{dec}{ }^{-1}$ at $25^{\circ} \mathrm{C}$. If the Heyrovsky step, eqn (5), is the rate-determining one, the measured Tafel slope should yield a value of about $40 \mathrm{mV} \mathrm{dec}{ }^{-1}$ in a low overvoltage region and $120 \mathrm{mV} \mathrm{dec}^{-1}$ in a high overvoltage region. If the Tafel desorption reaction occurs as the rate-determining step, eqn (6), it is characterized by a Tafel slope of $30 \mathrm{mV} \mathrm{dec}^{-1}$ in a low overvoltage range. The measured values of the Tafel slopes on $\mathrm{Ni}$ foam and $\mathrm{Pt}-\mathrm{C} / \mathrm{Ni}$ foam summarised in Table 1 suggest that the Heyrovsky reaction is the rate-determining step on both electrodes. This conclusion agrees with previous reports regarding the HER kinetics on $\mathrm{Ni}^{34,35}$ while the Heyrovsky step was also identified as the rate-determining one on nanosized Pt in alkaline media. ${ }^{36}$ Moreover, the observed values of the Tafel slope suggest high surface coverage by $\mathrm{H}_{\text {ads }}$. The HER mechanism at the RGO/Ni foam interface will be addressed in Section 3.4.

The exchange current density $\left(j_{0}\right)$ was used as a parameter to evaluate the activity of the catalyst towards the HER in water electrolysis. ${ }^{8}$ The attained values are again summarised in Table 1 . The $j_{0}$ of the RGO/Ni foam electrode was 12 times higher than that of the Ni foam electrode and 1.6 times higher than that of the Pt-C/Ni foam electrode.

\subsection{Performance of the MEA in an alkaline water electrolyser}

The load curves obtained for the materials under study are shown in Fig. 7D. In contrast to the bare Ni foam electrode, a very short activation potential region was observed for the RGO and Pt-C modified Ni foam electrodes. In most of the voltage range used the system performance was controlled by its ohmic resistance. At a cell voltage of $1.85 \mathrm{~V}$, which can be considered as the average cell voltage in industrial alkaline water electrolysers, the corresponding value of current density was $54 \mathrm{~mA} \mathrm{~cm}{ }^{-2}$ for the Ni foam cathode and $210 \mathrm{~mA} \mathrm{~cm}{ }^{-2}$ for the Pt-C-modified Ni foam. Under identical conditions the RGO-modified $\mathrm{Ni}$ foam cathode exhibited a current density of $223 \mathrm{~mA} \mathrm{~cm}{ }^{-2}$. This represents a very promising result.

\subsection{DFT modelling}

An obvious conclusion from the previous sections is that the HER activity of RGO/Ni is excellent, but the question is how does the combination of one rather poor HER catalyst (RGO) and one modest HER catalyst $(\mathrm{Ni})$ produce the catalyst that outperforms Pt?

Obviously, some kind of cooperative action must be operative. In order to rationalize the HER performance on the $\mathrm{Ni}$ foam-RGO electrode DFT modelling was used. Due to the complexity of the $\mathrm{Ni}$ foam-RGO interface, the interaction of hydrogen with graphene, RGO and Ni surface was investigated. Low $\mathrm{H}$ coverage of $1 / 32$ monolayers (ML) was considered on 

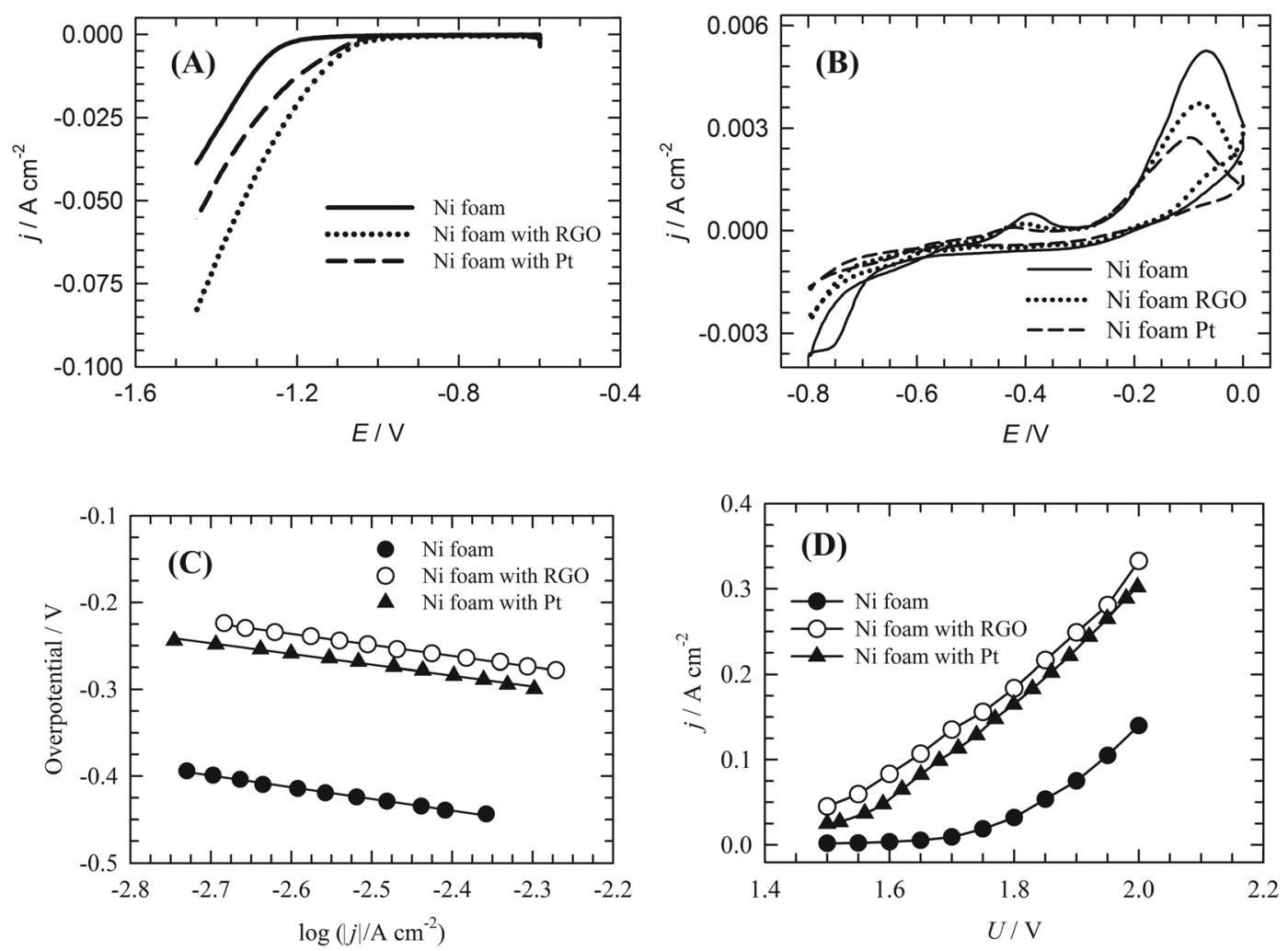

Fig. 7 (A) Pseudostationary linear sweep voltammetry curve, (B) cyclic voltammetric curve, (C) Tafel plot of the hydrogen evolution reaction. Experimental conditions: $22{ }^{\circ} \mathrm{C} ; 1 \mathrm{~mol} \mathrm{dm}^{-3} \mathrm{KOH}$ solution; working electrode: bare $\mathrm{Ni}$ foam, $0.15 \mathrm{mg} \mathrm{cm}^{-2} \mathrm{RGO}$-coated Ni foam \& $0.15 \mathrm{mg} \mathrm{cm}{ }^{-2} \mathrm{Pt}$ + qPPO binder (85:15). $\mathrm{Hg} / \mathrm{HgO}$ reference electrode; Pt counter-electrode; argon atmosphere; potential scan rate $10 \mathrm{mV} \mathrm{s}^{-1}$; and electrode area $3.8 \mathrm{~cm}^{-2}$ were used. (D) $\mathrm{V}-I$ characteristics of a single-cell electrolyser. Experimental conditions: $50{ }^{\circ} \mathrm{C} ; 10 \mathrm{wt} \% \mathrm{KOH}$ solution; anode: bare $\mathrm{Ni}$ foam; cathode: bare Ni foam, $0.15 \mathrm{mg} \mathrm{cm}{ }^{-2} \mathrm{RGO}$ coated Ni foam \& $0.15 \mathrm{mg} \mathrm{cm}^{-2} \mathrm{Pt}+$ qPPO binder (85: 15); electrode area $3.8 \mathrm{~cm}^{2}$; electrolyte flow rate $350 \mathrm{ml} \mathrm{min}{ }^{-1}$. Assignment of electrodes is indicated in the figures for all experiments.

Table 1 Tafel slopes and exchange current densities determined for bare $\mathrm{Ni}, \mathrm{RGO}$ and $\mathrm{Pt}-\mathrm{C}$ modified $\mathrm{Ni}$ foam electrodes in $1 \mathrm{M} \mathrm{KOH}$ solution

\begin{tabular}{lll}
\hline Catalyst & $\begin{array}{l}\text { Tafel slope } \\
\left(\mathrm{mV} \mathrm{dec}^{-1}\right)\end{array}$ & $\begin{array}{l}\text { Exchange current } \\
\text { density }\left(\mathrm{A} \mathrm{cm}^{-2}\right)\end{array}$ \\
\hline Ni foam & -144 & $6.76 \times 10^{-5}$ \\
RGO-Ni foam & -130 & $1.04 \times 10^{-3}$ \\
Pt-C/Ni foam & -133 & $7.24 \times 10^{-4}$
\end{tabular}

p-graphene and RGO. As a reference, we found that p-graphene binds $\mathrm{H}$ weakly, with the $\mathrm{H}$ binding energy amounting to $-0.84 \mathrm{eV}$ using a spin-restricted approach, while the inclusion of the spin polarization had a minor effect, decreasing $E_{\mathrm{b}}$ to $-0.89 \mathrm{eV}$. This result is in accordance with previous reports on $\mathrm{H}$-graphene interaction in the literature (see the overview provided by Ivanovskaya et $a{ }^{37}{ }^{37}$ ), which validates our model of the graphene layer.

With this benchmark we set two models of graphene containing hardly reducible O-groups which were found in the RGO reported here, namely, epoxy-graphene and hydroxylgraphene (Fig. 8, bottom). We observed the local change in the $\mathrm{C}-\mathrm{C}$ bond lengths and the corrugation of the graphene layer upon the introduction of O-functional groups, which indicates the disruption of the $\pi$ electronic system due to $\mathrm{sp}^{2} \rightarrow \mathrm{sp}^{3}$ rehybridization. This is also reflected in the change in the $\mathrm{C}-\mathrm{C}$ bond lengths in the vicinity of $\mathrm{O}$ functional groups which increases from $1.42 \AA$ to up to $1.51 \AA$. The latter value is between the bond lengths of a single and a double $\mathrm{C}-\mathrm{C}$ bond. The final result of the functionalization of graphene is the formation of unsaturated surface bonds, which consequently affects the chemisorption properties of RGO. To further validate our models, a comparison can be made with the work of Mkhoyan et al. ${ }^{38}$ The authors found experimentally the average roughness of the $\mathrm{O}$-containing graphene $(\mathrm{O}: \mathrm{C}$ ratio $1: 5)$ to be $0.6 \mathrm{~nm}$. In the present work we found that the layer roughness amounts to $0.72 \mathrm{~nm}$ for $\mathrm{C}_{32} \mathrm{O}_{4}$ and $1.1 \mathrm{~nm}$ for $\mathrm{C}_{32}(\mathrm{OH})_{4}$. For the $\mathrm{O}$ concentration investigated here, no pronounced band gap opening was observed for the two models of RGO, which is in agreement with the previous work on O-containing graphene. ${ }^{39}$ The ground states of the RGO models investigated here were found to be non-magnetic. More details on the models used here are provided in the recent work of Dobrota et al. ${ }^{40}$

The evaluated hydrogen binding energies on p-graphene and the RGO model surfaces (Table 2) indicate enhanced chemisorption upon the introduction of the O-surface groups on the graphene plane. Spin-polarization usually affects $E_{\mathrm{b}}$ to a very small extent and does not change the preference of the adsorption sites. Hydrogen chemisorption on the RGO model surfaces was tested at different sites selected on the basis of the 

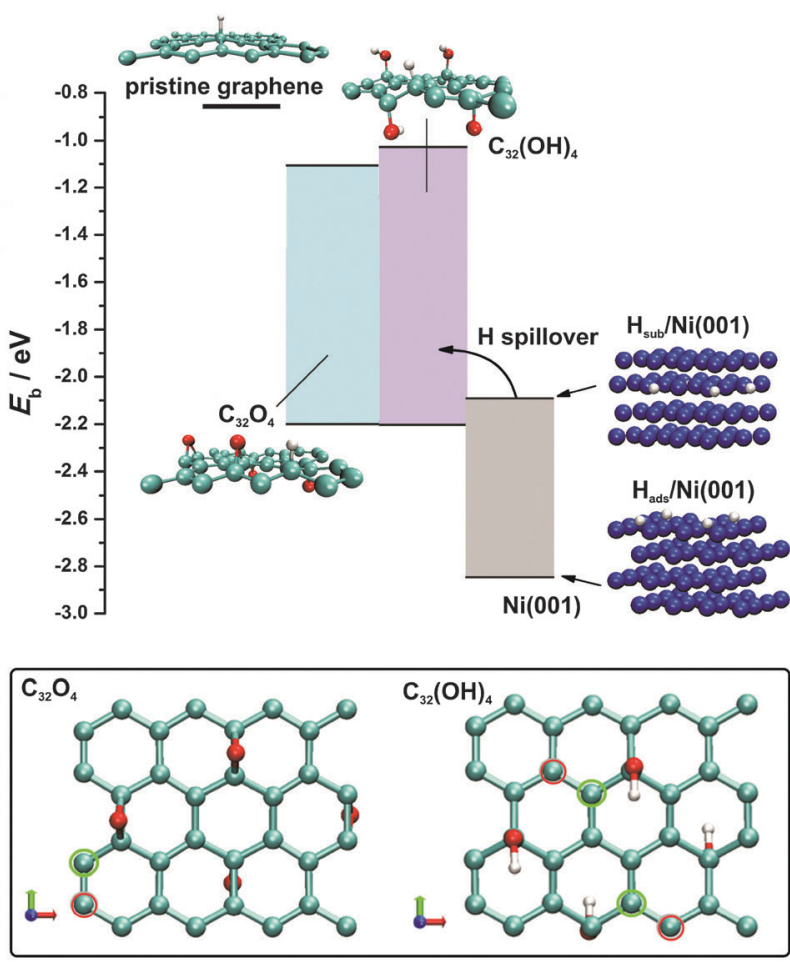

Fig. 8 Comparison of the hydrogen binding energies on the considered RGO model surfaces with hydrogen adsorption/absorption energetics on the $\mathrm{Ni}(001)$ surface. Shaded areas represent the range of hydrogen binding energies on a particular surface. Hydrogen binding energy on p-graphene is indicated by a thick horizontal line. Even at very low $\mathrm{H}$ coverage, $\mathrm{H}$ binding presents an energetically favourable alternative to the formation of subsurface $\mathrm{H}$ atoms in the $\mathrm{Ni}$ phase. At the bottom, two models of RGO employed in DFT calculations are presented: epoxy-graphene $\left(\mathrm{C}_{32} \mathrm{O}_{4}\right)$ and hydroxyl-graphene $\left(\mathrm{C}_{32}(\mathrm{OH})_{4}\right)$. The sites of the strongest (green circles) and the weakest bonding (red circles) of $\mathrm{H}$ on RGO are indicated.

symmetry, the electronic structure and the charge state (more than 40 different configurations). For both models we found that hydrogen binding energy is reduced to $-2.24 \mathrm{eV}$ (Table 2). According to eqn (2) this indicates that $\mathrm{H}$ binding on the RGO surface is $0.02 \mathrm{eV}$ endothermic with respect to $\mathrm{H}_{2}$. It was observed that the most reactive $\mathrm{C}$ atoms are located adjacent to O-functional groups (Fig. 8, bottom). This is understandable even at an intuitive level: the disturbance of the $\pi$ electronic system is most pronounced in the vicinity of the O-containing surface group, inducing the conversion of $\mathrm{sp}^{2}$ to $\mathrm{sp}^{3}$ bonds and the formation of unsaturated dangling bonds available for $\mathrm{H}$ chemisorption. Similar observations were

Table 2 Hydrogen binding energies on p-graphene and two analysed models of RGO. For RGO models, the highest and the lowest hydrogen binding energies $\left(E_{\mathrm{b}}\right)$ are given. Corresponding adsorption sites are denoted in Fig. 8 (bottom). The data for spin-restricted and spin-polarized calculations are included

\begin{tabular}{llllll}
\hline & \multicolumn{2}{l}{ Spin restricted } & & \multicolumn{2}{l}{ Spin-polarized } \\
\cline { 2 - 3 } Surface & $E_{\mathrm{b}, \max } / \mathrm{eV}$ & $E_{\mathrm{b}, \min } / \mathrm{eV}$ & & $E_{\mathrm{b}, \max } / \mathrm{eV}$ & $E_{\mathrm{b}, \min } / \mathrm{eV}$ \\
\hline p-Graphene & -0.84 & & -0.89 & \\
$\mathrm{C}_{32} \mathrm{O}_{4}$ & -2.18 & -0.83 & & -2.24 & -1.09 \\
$\mathrm{C}_{32}(\mathrm{OH})_{4}$ & -2.20 & -1.03 & & -2.24 & -1.04
\end{tabular}

previously made in the cases of other functional groups on the graphene layer. ${ }^{41,42}$ For example, formation of the dangling bonds upon increasing the oxidation level of graphene induces the agglomeration of the oxygen functionalities ${ }^{42}$ which in turn results in a stable oxidized graphene layer, ${ }^{43}$ even though a number of dangling bonds are formed. In spite of the enhanced $\mathrm{H}$ adsorption energies on RGO compared to p-graphene, $\mathrm{H}$ binding energies are still too low to promote effective $\mathrm{H}_{\text {ads }}$ formation, being the first step in the HER mechanism, which agrees with the low HER activity of oxidized graphene, as mentioned previously. ${ }^{20,21}$ Hence, the interim conclusion is that the initial $\mathrm{H}_{\text {ads }}$ formation must take place at the Ni surface via the Volmer reaction, and this is possible since we know that the RGO layer does not block the access of the electrolyte to the Ni foam surface (Fig. 7B).

In order to address the $\mathrm{H}-\mathrm{Ni}$ interaction, a $\mathrm{Ni}(001)$ surface was chosen since the $\mathrm{Ni}$ foam used in the experiments possesses a large number of surface defects and it was considered to be a better approximation of the HER catalyst surface than densely packed Ni(111). For this surface orientation, $\mathrm{H}$ binding energy amounting to $-2.84 \mathrm{eV}$ with a preference for 4 -fold sites (investigated coverage $0.25 \mathrm{ML}$ ) was found. This result is in excellent agreement with previous reports considering $\mathrm{H}$ interaction with $\mathrm{Ni}(001)$ (see ref. 44 for a detailed overview). Among low-index Ni surfaces, $\mathrm{Ni}(001)$ was found to bond to $\mathrm{H}$ the most strongly. ${ }^{44}$ Moreover, $\mathrm{H}$ binding energy on a Ni surface was previously found to depend weakly on surface coverage. ${ }^{45}$

HER catalytic activity trends are often rationalized in terms of a Volcano plot. ${ }^{46,47}$ The position of Ni on the Volcano was previously discussed in detail. ${ }^{46,48}$ Although the DFT calculations locate $\mathrm{Ni}$ on the HER volcano curve, calculations of the surface $\mathrm{H}$ diverge from the experimental behaviour as $\mathrm{Ni}$ forms hydrides under HER conditions with the $\mathrm{Ni}-\mathrm{H}$ bond energy amounting to $-2 \mathrm{eV}^{47}$ In order to account for this process, we also investigated hydrogen sorption into the Ni phase (quantified in the same manner as $\mathrm{H}$ adsorption, eqn (1), Experimental section). A stable hydrogen sorption site was found to be an octahedral one where $\mathrm{H}$ is located in the second subsurface layer with a bond energy of $-2.09 \mathrm{eV}$ (Fig. 8, see the structure denoted as $\left.\mathrm{H}_{\mathrm{sub}} / \mathrm{Ni}(001)\right)$. The formation of the subsurface hydride under HER operating conditions is considered to be the cause of $\mathrm{Ni}$ deactivation, ${ }^{49}$ while this process proceeds in spite of the high kinetic barrier (which was estimated to be almost $1 \mathrm{eV}$ ) due to the high effective fugacity of $\mathrm{H}$ under the corresponding experimental conditions. ${ }^{50}$ In this context, the build-up of subsurface hydride weakens the adsorption of $\mathrm{H}$ on the Ni surface, affecting HER kinetics, which is experimentally observed by the change in the Tafel slope and the exchange current density. ${ }^{49}$ Hence, the HER on a bare Ni electrode can be perceived as a complex process during which the formation of adsorbed $\mathrm{H}$ takes place, followed by its further recombination to $\mathrm{H}_{2}$ as well as its migration below the Ni surface. The latter process affects the initial step of $\mathrm{H}_{\mathrm{ads}}$ formation, leading to gradual deactivation, while under stationary conditions a certain degree of $\mathrm{Ni}$ coverage by $\mathrm{H}_{\text {ads }}$ is attained. For example, $\mathrm{Ni}$ coverage by $\mathrm{H}$ under HER conditions in $1.0 \mathrm{~mol} \mathrm{dm}^{-3} \mathrm{NaOH}$ is approximately $0.9 \mathrm{ML}$ when the overvoltage is below $-0.2 \mathrm{~V}^{51}$ 
This agrees with our conclusions based on the measured Tafel slope, and it is also in line with a strong $\mathrm{Ni}-\mathrm{H}_{\mathrm{ads}}$ bond.

The enhanced HER kinetics at the Ni-RGO interface, observed experimentally, suggests cooperative action between the $\mathrm{Ni}$ foam and RGO. By comparing the $\mathrm{H}$ binding energies on $\mathrm{Ni}$ and RGO (Fig. 8), it is concluded that the enhanced $\mathrm{H}$ chemisorption properties of RGO, compared to p-graphene, qualify it as a sink for $\mathrm{H}_{\mathrm{ads}}$ formed on the Ni surface. In other words, $\mathrm{H}_{\mathrm{ads}}$, intermediately formed on the Ni surface, migrates onto RGO instead of being engaged in the formation of subsurface Ni hydride which would ultimately hinder HER kinetics. Then, $\mathrm{H}_{\mathrm{ads}}$ recombines quickly on the RGO surface to form $\mathrm{H}_{2}$, which is also thermodynamically favoured as $\mathrm{H}$ adsorption on analysed RGO model surfaces is slightly endothermic with respect to the $\mathrm{H}_{2}$ (thermoneutral adsorption corresponds to $E_{\mathrm{b}}$ of $-2.26 \mathrm{eV}$, eqn (2)). By comparing $\mathrm{H}$ binding energies on RGO and Ni (Fig. 8), a thermodynamic barrier for the $\mathrm{H}$ spillover process can be estimated to be $0.6 \mathrm{eV}$, which can be overcome at room temperature. ${ }^{52}$ By this means, the Ni surface is constantly cleared and the HER kinetics is enhanced at the NiRGO interface as the new active sites are supplied for the discharge of $\mathrm{H}_{2} \mathrm{O}$. The facts that $\mathrm{H}_{\text {ads }}$ on RGO is endothermic with respect to $\mathrm{H}_{2}$ (suggesting low activation energy for the recombination) and that the thermodynamic barrier for the spillover process is low enough to enable the reaction to take place are, however, not sufficient. In order to provide fast $\mathrm{H}_{2}$ evolution by recombination of $\mathrm{H}_{\text {ads }}$ spilled to RGO, $\mathrm{H}_{\text {ads }}$ also need to have sufficiently high mobility so that two $\mathrm{H}_{\text {ads }}$ can meet and recombine. Recently it was shown that hydroxyl functional groups may facilitate $\mathrm{H}_{\mathrm{ads}}$ surface mobility on a graphene layer which stands in favour of our standing point. ${ }^{53}$ According to Fig. 8 the $\mathrm{H}$ spillover from Ni to RGO presents an energetically favourable alternative to the $\mathrm{H}_{2}$ formation on the Ni surface via a slow Heyrovsky reaction and the Ni hydride formation even at very low RGO coverage by adsorbed $\mathrm{H}$. On the other hand, previous theoretical results by Singh et $a .^{52}$ suggest that hydrogenation of p-graphene can enhance $\mathrm{H}$ spillover from $\mathrm{Pd}_{4}$ clusters. Hence, it is expected that hydrogenation of RGO will further increase $\mathrm{H}_{\text {ads }}-\mathrm{RGO}$ binding energy, making the spillover process even more feasible. This reinforces our conclusion regarding the mechanism of the enhanced HER activity of the RGO/Ni foam electrode. The $\mathrm{H}$ spillover onto p-graphene is energetically highly unfavourable (Fig. 9) with a barrier of almost $2 \mathrm{eV}$, indicating the crucial role of the O-containing groups of RGO for enhanced HER activity of the $\mathrm{RGO} / \mathrm{Ni}$ foam electrode. It should be noted that the $\mathrm{H}$ spillover is consistent with the experimentally measured Tafel slope for the $\mathrm{RGO} / \mathrm{Ni}$ electrode. If $\mathrm{H}_{2}$ is formed via the recombination of the spilled $\mathrm{H}_{\text {ads }}$ from the Ni foam to the RGO layer, which should be a fast process, then the $\mathrm{H}_{2} \mathrm{O}$ discharge to $\mathrm{H}_{\text {ads }}$ on the Ni foam (Volmer reaction) determines the kinetics of the $\mathrm{H}_{2}$ formation. If this is true, then the expected Tafel slope should be $-120 \mathrm{mV}$ $\operatorname{dec}^{-1}$, which matches quite well with the measured value of $-130 \mathrm{mV} \mathrm{dec}{ }^{-1}$.

In addition to the $\mathrm{RGO} / \mathrm{Ni}$ foam interface demonstrated here, a natural question arises whether some other nanostructured carbon such as carbon nanotubes (CNT) could provide similar action to RGO being a $\mathrm{H}_{\text {ads }}$ acceptor under HER conditions. If the

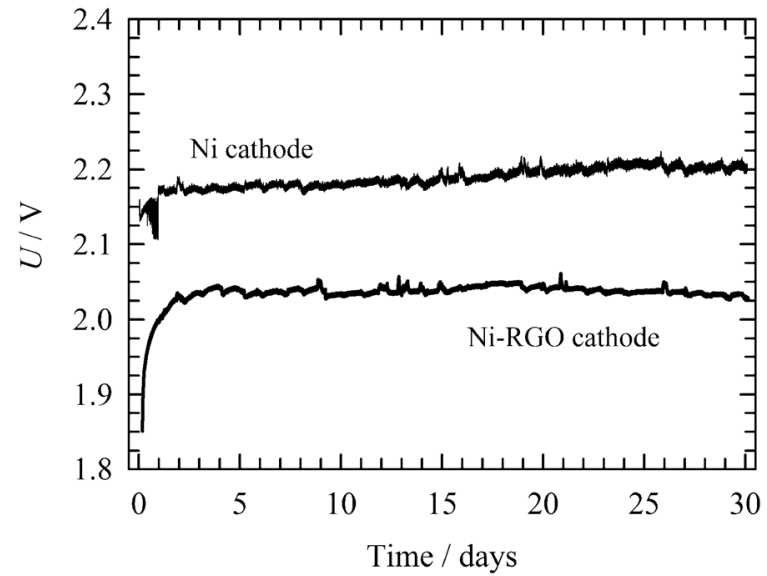

Fig. 9 Long-term stability test of a single-cell water electrolyser. Experimental conditions: $50{ }^{\circ} \mathrm{C}$; current density $265 \mathrm{~mA} \mathrm{~cm}^{-2}$; 10 wt\% $\mathrm{KOH}$ solution; anode: bare $\mathrm{Ni}$ foam; cathode: $0.15 \mathrm{mg} \mathrm{cm}^{-2} \mathrm{RGO}$-coated $\mathrm{Ni}$ foam or bare $\mathrm{Ni}$ foam (indicated in the figure); electrode area $3.8 \mathrm{~cm}^{2}$;

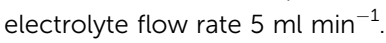

thermodynamic parameters related to the strength of the $\mathrm{H}_{\mathrm{ads}}$ interaction with the CNT surface are considered it seems that such a kind of operation could be possible but critically dependent on the structure of the CNTs. ${ }^{54}$ There are experimental reports which support this conclusion, demonstrating $\mathrm{H}$ spillover in metal-loaded CNTs. ${ }^{55,56}$ For example, Bhowmick et al. observed $\mathrm{H}$ spillover upon the exposure of the Pt-single wall CNT composite to molecular hydrogen, and confirmed the formation of new $\mathrm{C}-\mathrm{H}$ bonds using XPS, as done here later on. ${ }^{56}$ On the other hand, such composite materials has not been employed as the cathode material for water electrolysis and their performance with respect to the RGO/Ni foam electrode cannot be estimated at this point. The questions are also whether the CNT/Ni system can be prepared in the way similar to the RGO/Ni counterpart and how the performance would be impacted by the functionalization of CNTs.

\subsection{Effect of a cathode catalyst layer on the stability of the alkaline water electrolyser}

The long-term stability of the RGO-modified Ni foam electrode containing MEA was investigated in comparison to the bare $\mathrm{Ni}$ foam cathode by continuous operation at $265 \mathrm{~mA} \mathrm{~cm}{ }^{-2}$, in $10 \mathrm{wt} \% \mathrm{KOH}$ solution at $50{ }^{\circ} \mathrm{C}$. The continuous long-term stability test shown in Fig. 9 indicates that the cell voltage increases with time, reaching a stable value after 2 days. A further increase in the cell voltage, indicating cathode inhibition or RGO catalyst degradation, was not observed during the next 30 days long-term process. This implies good RGO stability for the HER under conditions of alkaline water electrolysis. By contrast, the bare Ni foam cathode shows a higher cell voltage over the polarization period under study. Cathodes for industrial electrolysers have to possess good durability not just under continuous, but also intermittent operation corresponding to the shutdown of the electrolyser for maintenance or as a response to unstable power sources, such as renewables (e.g. wind and solar). After 30 days of the continuous process, the operational conditions were changed 


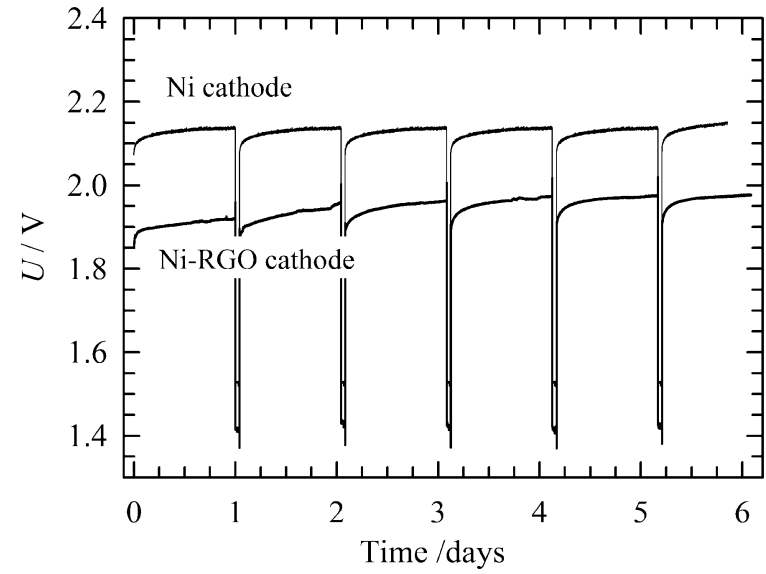

Fig. 10 Long-term intermittent stability test of a single-cell water electrolyser. Experimental conditions: $50{ }^{\circ} \mathrm{C}$; current load $265 \mathrm{~mA} \mathrm{~cm}{ }^{-2}, 1$ hour current density was changed to $2.6 \mu \mathrm{A} \mathrm{cm} \mathrm{cm}^{-2}$ after every 23 hours of operation at working current load; $10 \mathrm{wt} \% \mathrm{KOH}$ solution; anode: bare Ni foam; cathode: $0.15 \mathrm{mg} \mathrm{cm}^{-2} \mathrm{RGO}$-coated $\mathrm{Ni}$ foam or bare $\mathrm{Ni}$ foam (indicated in the figure): electrode area $3.8 \mathrm{~cm}^{2}$; electrolyte flow rate $5 \mathrm{ml} \mathrm{min}$.

to discontinuous for 5 days. First, the electrodes were polarized at a constant current density of $265 \mathrm{~mA} \mathrm{~cm}{ }^{-2}$ for 23 hours. Then the current density was reduced to $2.6 \mu \mathrm{A} \mathrm{cm}^{-2}$ for 1 hour. During the intermittent periods, the electrode was depolarized by the electrochemical discharge reactions releasing electrochemically adsorbed hydrogen in a molecular form. At the same time, the hydrogen adsorbed on the Ni surface also partly diffused into the bulk of the electrode. In these two ways the active sites are regenerated. As can be seen in Fig. 10, after each intermittent period the cell voltage started at a value lower than at the end of the previous cycle. The final voltage achieved at the end of the individual cycles gradually increased, but never attained a value of the voltage recorded for the stable polarization (Fig. 9). A similar behaviour was observed for bare $\mathrm{Ni}$ cathode. Although the difference between RGO-Ni and bare $\mathrm{Ni}$ was slightly reduced over the period of cell intermittent operation, this change was not significant. Similarly to the case of constant load, the main decrease in the difference in voltage appears within first 2 to 3 days period. Afterwards it stabilises. The voltage variation within each cycle is due to the repeated desorption of the hydrogen accumulated on the electrode surface during a switch-off period, leading to repeated regeneration of the active sites. The intermittent electrolysis test thus supports the claim of the outstanding stability of the RGO catalyst.

The SEM micrograph after 35 days (30 days continuous + 5 days intermittent) of electrolysis is presented in Fig. 11A and B. As can be seen, the electrode surface was damaged to a certain extent, as compared with the surface prior electrolysis as shown in Fig. 3A and B. These small changes can, however, be considered to have a negligible impact on the HER potential.

Furthermore, after long-term exposure the chemical composition of the RGO catalytic layer was examined by means of XPS. The XPS spectra survey scan in Fig. 12A reveal that the $\mathrm{C}$ and $\mathrm{O}$ atomic ratio was 3.45 , which indicates a greater reduction of

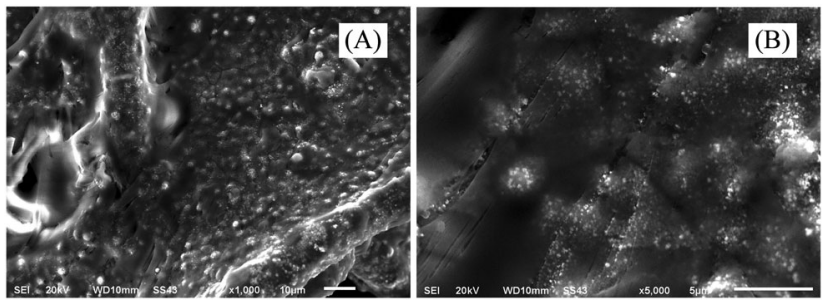

Fig. 11 Surface morphology of the RGO/Ni foam catalytic layer after a 35 day (30 days continuous +5 days intermittent) long-term electrolysis test.
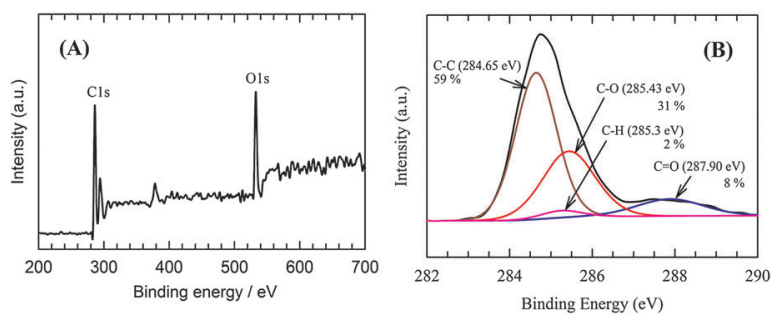

Fig. 12 The XPS survey spectra (A) and C1s fitting curve (B) of the RGO catalytic layer after a 35 day (30 days continuous +5 days intermittent) long-term stability test.

the RGO compared to the electrode prior to electrolysis as shown in Fig. 2B. The C1s spectra of the RGO catalyst after electrolysis are shown in Fig. 12B. The intensity of the $\mathrm{C}-\mathrm{C}$ (59\%) bond signal increased and that of the peak corresponding to the $\mathrm{C}-\mathrm{O}$ or $\mathrm{C}-\mathrm{OH}(31 \%)$ bonds decreased. This could be explained by virtue of the reduction of the $\mathrm{C}-\mathrm{O}$ or $\mathrm{C}-\mathrm{OH}$ bonds. On the other hand, the $\mathrm{C}=\mathrm{O}(8 \%)$ bond peak intensity increased, which may have been caused by the minor extent of the oxidation of the $\mathrm{C}-\mathrm{O}$ or $\mathrm{C}-\mathrm{OH}$ bonds in the intermittent electrolysis period. The additional peak (Fig. 12B) at 285.3 (2\%) can be assigned to the binding energy of the $\mathrm{C}-\mathrm{H}$ bond. ${ }^{57}$ While the observation of the $\mathrm{C}-\mathrm{H}$ moieties is a direct confirmation of $\mathrm{H}$ spillover on the RGO surface, ${ }^{56}$ its low contribution to the overall C1s spectra is in harmony with the endothermic formation of $\mathrm{H}_{\text {ads }}$ on RGO (Table 2). Since it can be observed that different $\mathrm{C}$ atoms bind $\mathrm{H}_{\text {ads }}$ with differing strengths on the RGO surface, it is suggested that $\mathrm{H}_{\mathrm{ads}}$ only remained at the strongest binding sites of RGO under UHV conditions in the XPS chamber. However, according to our results, the rapid recombination of $\mathrm{H}_{\mathrm{ads}}$ on $\mathrm{RGO}$ is, in fact, what makes the RGO/Ni foam electrode such an excellent HER catalyst.

\section{Conclusions}

In this study, it has been reported that the RGO-modified nickel foam electrode is a superb novel HER catalyst in alkaline medium. Under identical conditions, the RGO/Ni catalyst even surpasses the Pt-C catalyst in terms of HER activity. Experimental measurements were complemented by DFT calculations which led to the following conclusion regarding the crucial role of RGO in the RGO-modified Ni foam electrode: it enables $\mathrm{H}$ spillover from the $\mathrm{Ni}$ foam, acting as an acceptor of $\mathrm{H}$ atoms 
obtained upon $\mathrm{H}_{2} \mathrm{O}$ discharge on $\mathrm{Ni}$ foam. This facilitates the formation of free active sites on the $\mathrm{Ni}$ phase, which is necessary for the HER to proceed, and also of an alternative path for $\mathrm{H}_{2}$ production via the recombination of the spilled $\mathrm{H}_{\mathrm{ads}}$ from the Ni foam to RGO. Such an action is enabled by the unique reactivity of RGO rendered by its $\mathrm{O}$ surface groups. The HER kinetics on the RGO/Ni foam is determined by the $\mathrm{H}_{2} \mathrm{O}$ discharge with the formation of the adsorbed $\mathrm{H}$, while the $\mathrm{H}$ spillover enables an effective pathway for the removal of intermediately formed $\mathrm{H}_{\text {ads }}$. While the proposed mechanism of HER activity enhancement is a well-known concept in electrochemistry, the use of RGO as a surface modifier, and not as a support for nanosized catalysts, opens up a new perspective for the design of novel HER catalysts.

The 35 day test manifested excellent stability of this electrode. The overall properties of the non-noble RGO/Ni foam electrode make an excellent case for an alternative to the noble metal-based HER catalyst.

\section{Acknowledgements}

We acknowledge funding support from the Ministry of Education, Youth and Sports of the Czech Republic under specific university research (MSMT No. 20/2015), and from the Serbian Ministry of Education, Science and Technological Development under project no. III45014.

\section{References}

1 J. A. Turner, Science, 2004, 305, 972-975.

2 T. N. Veziroglu, Int. J. Hydrogen Energy, 2000, 25, 1143-1150.

3 J. B. Yadav, J. W. Park, Y. J. Cho and O. S. Joo, Int. J. Hydrogen Energy, 2010, 35, 10067-10072.

4 C. C. Pavel, F. Cecconi, C. Emiliani, S. santicioli, A. Scaffidi, S. Catanorchi and M. Comotti, Angew. Chem., Int. Ed., 2014, 53, 1378-1381.

5 J. Hnát, M. Paidar, J. Schauer and K. Bouzek, Int. J. Hydrogen Energy, 2014, 39, 4779-4787.

6 Y. Leng, G. Chen, A. J. Mendoza, T. B. Tighe, M. A. Hickner and C. Y. Wang, J. Am. Chem. Soc., 2012, 134(22), 9054-9057.

7 L. Wu, Y. He, T. Lei, B. Nan, N. Xu, J. Zou, B. Huang and C. T. Liu, Energy, 2013, 63, 216-224.

8 C. I. Muller, T. Rauscher, A. Schmidt, T. Schubert, T. Weißgärber, B. Kieback and R. Röntzsch, Int. J. Hydrogen Energy, 2014, 39, 8926-8937.

9 D. Chanda, J. Hnát, M. Paidar, J. Schauer and K. Bouzek, J. Power Sources, 2015, 285, 217-226.

10 S. Seetharaman, R. Balaji, K. Ramya, S. K. Dhathathreyan and M. Velan, Int. J. Hydrogen Energy, 2013, 38, 14934-14942.

11 Q. Liu, J. Jin and J. Zhang, ACS Appl. Mater. Interfaces, 2013, 5(11), 5002-5008.

12 Y. Liang, Y. Li, H. Wang, J. Zhou, J. Wang, T. Regier and H. Dai, Nat. Mater., 2011, 10, 780.

13 H. A. Becerril, J. Mao, Z. Liu, R. M. Stoltenberg, Z. Bao and Y. Chen, ACS Nano, 2008, 2, 463-470.
14 C. G. Navarro, R. T. Weitz, A. M. Bittner, M. Scolari, A. Mews, M. Burghard and K. Kern, Nano Lett., 2007, 7, 3499-3503.

15 H. Tang, K. Dou, C. C. Kaun, Q. Kuanga and S. Yang, J. Mater. Chem. A, 2014, 2, 360-364.

16 Y. Li, H. Wang, L. Xie, Y. Liang, G. Hong and H. Dai, J. Am. Chem. Soc., 2011, 133(19), 7296-7299.

17 J. Yang, D. Voiry, S. J. Ahn, D. Kang, A. Y. Kim, M. Chhowalla and H. S. Shin, Angew. Chem., Int. Ed., 2013, 52, 13751-13754.

18 G. F. Cai, J. P. Tu, J. Zhang, Y. J. Mai, Y. Lu, C. D. Gu and X. L. Wang, Nanoscale, 2012, 4, 5724-5730.

19 X. Li, X. Wang, L. Zhang, S. Lee and H. Dai, Science, 2008, 319(5867), 1229-1232.

20 C. B. Ma, X. Qi, B. Chen, S. Bao, Z. Yin, X. J. Wu, Z. Luo, J. Wei, H. L. Zhang and H. Zhang, Nanoscale, 2014, 6, 5624-5629.

21 S. Sarkar and S. Sampath, Chem. Commun., 2014, 50, 7359-7362.

22 O. S. Kwon, T. Kim, J. S. Lee, S. J. Park, H. W. Park, M. Kang, J. E. Lee, J. Jang and H. Yoon, Small, 2013, 9(2), 248-254.

23 S. J. Wang, Y. Geng, Q. Zheng and J. K. Kim, Carbon, 2010, 48(6), 1815-1823.

24 K. Yu, Z. Wen, H. Pu, G. Lu, Z. Bo, H. Kim, Y. Qian, E. Andrew and S. Mao, J. Mater. Chem. A, 2013, 1(2), 188-193.

25 A. K. Geim and K. S. Novoselov, Nat. Mater., 2007, 6(3), 183-191.

26 A. K. Singh, M. A. Ribas and B. I. Yakobson, ACS Nano, 2009, 3, 1657-1662.

27 K. Spyrou, D. Gournis and P. Rudolf, ECS J. Solid State Sci. Technol., 2013, 2(10), M3160-M3169.

28 L. Wang, U. Stimming and M. Eikerling, Electrocatalysis, 2010, 1, 60-71.

29 D. C. Marcano, D. V. Kosynki, J. M. Berlin, A. Sinitskii, Z. Sun, A. Slesarev, L. B. Alemany, W. Lu and J. M. Tour, ACS Nano, 2010, 4, 4806-4814.

30 J. Hnát, M. Paidar, J. Schauer, J. Zitka and K. Bouzek, J. Appl. Electrochem., 2012, 42, 545-554.

31 P. Giannozziet, et al., J. Phys.: Condens. Matter, 2009, 21, 395502.

32 J. P. Perdew, K. Burke and M. Ernzerhof, Phys. Rev. Lett., 1996, 77, 3865-3868.

33 H. J. Monkhorst and J. D. Pack, Phys. Rev. B: Solid State, 1976, 13, 5188-5192.

34 P. Quaino, F. Juarez, E. Santos and W. Schmickler, Beilstein J. Nanotechnol., 2014, 5, 846-854.

35 J. M. Jaksic, M. V. Vojnovic and N. V. Krstajic, Electrochim. Acta, 2000, 45, 4151-4158.

36 W. Sheng, H. A. Gasteiger and Y. S. Horn, J. Electrochem. Soc., 2010, 157(11), B1529-B1536.

37 V. V. Ivanovskaya, A. Zobelli, D. Teillet-Billy, N. Rougeau, V. Sidis and P. R. Briddon, Eur. Phys. J. B, 2010, 76, 481-486.

38 K. A. Mkhoyan, A. W. Contryman, J. Silcox, D. A. Stewart, G. Eda, C. Mattevi, S. Miller and M. Chhowalla, Nano Lett., 2009, 9, 1058-1063.

39 J. Ito, J. Nakamura and J. A. Natori, Appl. Phys., 2008, 103, 113712. 40 A. S. Dobrota, I. A. Pašti and N. V. Skorodumova, Electrochim. Acta, 2015, 176, 1092.

41 V. Georgakilas, M. Otyepka, A. B. Bourlinos, V. Chandra, N. Kim, K. C. Kemp, P. Hobza, R. Zboril and K. S. Kim, Chem. Rev., 2012, 112, 6156. 
42 N. Ghaderi and M. Peressi, J. Phys. Chem. C, 2010, 114, 21625.

43 S. Zhou and A. Bongiorno, Sci. Rep., 2013, 3, 2484, DOI: 10.1038/srep02484.

44 A. Mohsenzadeh, K. Bolton and T. Richards, Surf. Sci., 2014, 627, 1-10.

45 J. K. Nørskov, T. Bligaard, A. Logadottir, J. R. Kitchin, J. G. Chen, S. Pandelov and U. Stimming, J. Electrochem. Soc., 2005, 152, J23-J26.

46 S. Trasatti, J. Electroanal. Chem. Interfacial Electrochem., 1972, 39, 163-184.

47 W. Sheng, M. Myint, J. G. Chen and Y. Yan, Energy Environ. Sci., 2013, 6, 1509-1512.

48 W. Schmickler and S. Trasatti, J. Electrochem. Soc., 2006, 153, L31-L32.

49 J. G. Highfield, E. Claude and K. Oguro, Electrochim. Acta, 1999, 44, 2805-2814.
50 B. Baranowski, Hydride formation at high hydrogen pressure, in Metal Hydrides, ed. G. Bambakidis, Plenum Press, 1981, p. 193.

51 J. M. Jakšić, M. V. Vojnović and N. V. Krstajić, Electrochim. Acta, 2000, 45, 4151-4158.

52 A. K. Singh, M. A. Ribas and B. I. Yakobson, ACS Nano, 2009, 3, 1657-1662.

53 A. D. Lueking, G. Psofogiannakis and G. E. Froudakis, J. Phys. Chem. C, 2013, 117, 6312.

54 V. Barone, J. Heyd and G. E. Scuseria, J. Chem. Phys., 2004, 120, 7169.

55 C.-H. Chen and C.-C. Huang, Microporous Mesoporous Mater., 2008, 109, 549.

56 R. Bhowmick, S. Rajasekaran, D. Friebel, C. Beasley, L. Jiao, H. Ogasawara, H. Dai, B. Clemens and A. Nilsson, J. Am. Chem. Soc., 2011, 133, 5580.

57 S. Mukherjee, B. Ramalingam and S. Gangopadhyay, J. Mater. Chem. A, 2014, 2, 3954-3960. 